\title{
Information Systems as an Academic Discipline
}

Looking Back, Looking Forward, and Ensuring the

Future

Gordon B. Davis

Honeywell Professor of Management Information Systems, Emeritus

University of Minnesota

gdavis@csom.umn.edu

\section{Introduction}

In an organization of any size, there is an organization function responsible for the technology, activities and personnel to support its technology-enabled work systems and the information and communication needs of the organization. There is an academic discipline that teaches those who build, acquire, operate and maintain the systems and those who use the systems. Both the organization function and the academic discipline have developed over a period of 55 years (but primarily in the last 40 years).

There have been two fundamental forces driving the formation of a new organization function and the new technology-enabled systems in organizations. One is the availability of powerful computer and communications technology; the other is the desire of organizations to use the capabilities in organization work. The result has been revolutionary as new capabilities and new affordances have been applied to the activities of organizations. A new academic discipline has emerged. This period of rapid innovation in organizations has resulted in successes, challenges, failures, and surprises.

$I$ have been a participant and an observer of this period of change. The paper will survey key developments (from my perspective) that have brought us to the present conditions in use of information and communications technology in organizations and the current status of the academic discipline. I will note the role of IFIP TC8 (Information Systems). It has been important in several key developments, but not in all of them. I will identify some of my observations about the value added by TC8. 
We are perhaps at a critical juncture. There are both negative and positive forces affecting the future. The question is how to respond to them. To ensure a productive, viable future for the organization function and academic discipline, both those in the organization function and those in academia need to be proactive. In this paper, I summarize some thoughts on the future of the academic field and what it should do to ensure its future.

Many of the ideas in the paper have been formulated over the last 40 years. They are based on my experiences and discussions with a large number of colleagues. I paraphrase or reuse ideas from papers I have written that have been published in proceedings. Two of my papers that were especially significant sources in preparing this overview paper are $[1,2]$. Much of my experience was rooted in the MIS program at Minnesota founded by me, Gary Dickson, and Tom Hoffmann in 1968. See also $[3,4]$

The paper begins with some definitions, summarizes some key historical events related to the field including some comments about the delay in establishing information systems compared to establishing computer science, key factors in the emergence of an international community for information systems as an academic discipline, the role of IFIP and TC8 (Information Systems) in nourishing the new academic discipline, and thoughts about the future of the academic discipline and what needs to be done to secure its future.

\section{Definitions}

In organizations, the term Information System (IS) or some equivalent label refers to both:

- the systems that deliver information and communication services to an organization

- the organization function that plans, develops, operates, and manages the information systems

The IS function may be organized as a separate organization function with a high level executive with a title such as Chief Information Officer (CIO), or it may be organized as a unit under an operations or financial executive. Because of the use of information and communications technology, the function and its services is often referred to as Information Technology or IT.

There are four important parts of the organization function for information systems, and these parts are found in the research and teaching activities of the academic discipline. These can be characterized as IS management, infrastructure, systems acquisition and support, and databases.

- The management, personnel and operations of the function. This includes planning and co-alignment of information system strategy and organization strategy and the evaluation and justification of organization investment in IS.

- Planning and implementing an infrastructure of hardware, system software, and enterprise systems. 
- Building or acquiring, implementing, and supporting systems. This includes tailoring enterprise software to fit user needs and individual applications for individuals, groups, and functions. It also includes ongoing support and maintenance.

- Designing, building, and maintaining internal databases and access to external sources of data.

The name for the information systems academic discipline more or less mirrors the organization use. Note that I refer to the "academic discipline" and "academic field", using the terms as equivalent. Some of the names that are used for the discipline are:

- Information Systems

- Management Information Systems

- Information Management

- Management of Information Systems

- Informatics (usually modified by organization, administration, or similar terms)

Some academics have argued for the use of Informatics instead of Information Systems as the general name for the academic discipline. It seems to be a broader term. However, it is difficult and probably unnecessary to change common usage. As a historical note, in the early 1970s, some of us proposed to use Informatics, but in the USA the name was copyrighted by a firm that threatened to prevent its use on journals, etc. The firm no longer exists.

The domain of the academic discipline of information systems seems very broad. The reason for the broad domain is the fact that support and services are being provided to different functions and activities in the organization and also to customers and suppliers. The domain of information systems can be described as:

- The core knowledge that is fundamental to information systems in organizations. This core knowledge includes modeling of organization transactions and behaviors, modeling of data and design of databases, and systems concepts (including socio-technical systems).

- Knowledge of the activities, operations and management of the information systems function. The activities assume understanding of communications and information processing technologies.

- Knowledge of the applications and services provided to individuals, groups, and functions in the organization. This domain is shared with the users of the applications and services.

Two critical features of Information Systems as an academic field today are its organizational context and its international orientation. Computers and communications may affect many fields of study within the university that do not have an organization context. Examples are medical informatics, educational technology, etc. However, information systems, as an academic discipline, is tied to the use of information and communications technology in organizations. This is true even if the discipline is positioned outside a school of organization studies. The second feature of the field is its international orientation. Most academic disciplines 
within the broad field of organizations, management, or economic sciences developed within the context of a country or a region. Examples are accounting, marketing, and industrial relations. They are working to be international. The academic discipline of information systems became international very quickly and has maintained that outlook.

\section{Historical Development}

Computing (Computer Science) developed as an academic field of research and degree programs much more quickly than information systems. It developed within the academic context of engineering or mathematics. Academic researchers developed computing devices during the 1940s for use in code breaking. In the last half of the 1940s, many university research groups were engaged in building one-ofa-kind computers to test various ideas on design. By 1951, the UNIVAC I was available as a commercial computer and the LEO computer, developed by the Lyons Tea Company and Cambridge University, became operational. Scientific organizations for computing were organized in several countries. There were enough computing organizations that IFIP was organized in 1960 as an international federation of computing societies.

Unlike computing, information systems as a separate subject took a number of years to emerge. Although many universities throughout the world had individual researchers engaged in research and teaching relative to information systems, the academic homes for these pioneers varied considerably. Three events illustrate the delay in formation of a formal field of study and research: the first professor was 1965, the first formal program was 1968, and it was not until 1976 that IFIP organized TC8, recognizing information systems as a separate field within computing.

A few dates mark some noteworthy events leading to recognition of information systems as a separate field within the broad range of computing disciplines. Any person engaged in historical research knows that it is not easy to identify the "first" person or organization that did something important. There were usually many persons or organizations working on the problem or initiating the changes, and the ones identified in the literature are among the pioneers but not necessarily "the first." Given that caveat, the following are some interesting "firsts."

- First business use of computers in UK (the LEO computer); first use by Census Bureau in USA of the UNIVAC I

- First business use of a commercial computer in USA by GE (UNIVAC I)

- First speculation of importance to business of computers in Harvard Business Review

- Forming of International Federation for Information Processing (IFIP)

- Börje Langefors appointed as professor (joint chair at the Royal Institute of Technology and the University of Stockholm) in Information Processing, with special emphasis on Administrative Data Processing. 
- First formal MIS academic degree programs in the USA (M.S. and $\mathrm{Ph} . \mathrm{D}$.) at University of Minnesota.

- Establishment of organization for information system executives (CIOs); first called Society for Management Information Systems and now Society for Information Management (SIM)

- Establishment of IFIP technical committee on information systems (TC8)

- The journal MIS Quarterly started at the University of Minnesota (but not the first journal in the field)

- First International Conference on Information Systems (ICIS)

- Formation of Association for Information Systems (AIS) as an international academic organization with an international governance structure. Merger in 2001 of AIS and ICIS. AIS alliances with regional conferences in Europe, Asia, and America (ECIS, PACIS, and AMCIS).

In my view, the delay in recognition of information systems as a separate computing discipline and an important field in management and organizations was caused by three major factors: the time lag between the introduction of computers and the recognition of an interesting, important IS organization function and interesting, important IS research issues; the diverse backgrounds of academic researchers with interests in information systems and conflicting loyalties with existing academic/professional societies; and conferences and journals that accepted IS research results. These issues explain much of the delay, but strong informal networks of academic colleagues were emerging and would finally lead to a strong IS academic community.

- The time lag between the introduction of computers and the recognition of an interesting, important organization function and interesting, important IS research issues. Punched card data processing was not an interesting academic subject for teaching or research. Early use of computers focused on simple transaction processing, so it didn't look interesting. What was interesting was the possibility of improved analysis, improved managerial reporting, and improved decision making. As organizations developed and implemented computer-based data processing systems, they experienced many interesting methods problems such as requirements determination, development methodologies, implementation, design of work systems, and evaluation.

- The diverse backgrounds of academic researchers with interests in information systems and conflicting loyalties with existing academic/professional organizations. Early academic researchers came from a variety of backgrounds such as management, accounting, computer science, and management science. There was no sense of urgency to establish a new academic discipline since doctoral students in the 1960 s who were interested in information systems took doctorates in these existing subjects. It was not until 1968 that the first formal doctoral program in information systems in North America was established at the University of Minnesota (along with an MIS research center). 
- Conferences and journals that accepted IS research results. Given the diverse backgrounds of researchers and the diverse department affiliations, the early researchers looked to their home discipline for opportunities to present and publish their work. Several organizations formed special interest groups around the issues of information systems and sponsored conferences and IS conference tracks within their regular conferences. Because there were existing conferences and publishing outlets for IS research, there was limited urgency to establish a separate academic discipline with its own conferences and journals.

\section{International Differences in the Development of an International Discipline}

Even though there is today an international discipline of information systems with broad acceptance of the major research themes and research methods, there were some regional differences in emphasis in the development of academic research. All major topics related to information systems were being developed in all countries, but the level of interest and the level of activity were different

Research on the four parts of the organization function (IS management, infrastructure, systems acquisition and support, and databases) do not differ significantly across the world. However, in the early development of the IS academic discipline, there were differences in the kind of research that was most prominent in the regions.

- The early work on development methods was dominated by European researchers. In the IFIP TC8 WG8.1 series of working conferences on methods, most of the contributions were by Europeans. There were some USA researchers, especially on automated development methods (e.g., Daniel Teichroew).

- There were a variety of early studies on management of the IS function including the management of personnel and operations. These tended to come from North America with Harvard and MIT providing significant inputs. Two noteworthy examples were Nolan's stage theory for managing the function and the Harvard studies on competitive advantage through information systems.

- The most powerful and insightful early research on evaluation of technology-enabled systems was done in the UK and Scandinavia by researchers based on socio-technical concepts and organization behavior. Notable were researchers associated with WG8.2 such as Enid Mumford.

- The use of information systems to improve management was a common topic. The period of emergence of computers was also a period in which management science and operations research were applying new quantitative methods to management. Some of the strongest early research was on use of models that depended on computers and on decision support systems. This research had strong beginnings in MIT 
and other North American universities. There was significant experimental research, dominated in the early stages by North American academics, into cognitive style as a basis for the design of management reports and other decision support.

- The incidence of different research methods was somewhat different by region in the early development of the discipline. Positivist methods emphasizing analysis of data were dominant in North America; interpretive methods were more accepted in Europe. Design science methods involving the building of artifacts were used more commonly in Europe.

\section{Some Important Developments or Events Supporting the Emergence of an International Academic Discipline of Information Systems}

In explaining how it happened, I believe there were seven critical events or developments that made it possible to have an international academic discipline for information systems. These are the development of computing devices and computer science, the use of English as the common language for computing-related disciplines, the formation of the International Federation for Information Processing and its Technical Committee 8 (Information Systems), international efforts by scholars in several countries, locating the IFIP TC8 working conferences internationally, the founding of the International Conference on Information Systems (ICIS), and the founding of the Association for Information Systems (AIS) with an international governance structure.

\section{Development of computing devices and computer science}

Without the development of computing devices, information systems would not have become a field of study and research. It was also necessary to have academic interest and research in the hardware and software that would be employed in information systems.

After World War II, there was interest in many universities around the world in the design and development of computing machinery. The community of researchers shared designs and experiences, so the development of computing machinery was an international effort. Very early in this period of development, Computer Science societies were established by a combination of academics and practitioners. Each country tended to have its own organization. Computer Science as an academic discipline provided for academic research and teaching in algorithms for computing, system software, software development methods, and data base methods. These were important in providing scientific support for the tools and methods needed by information systems.

2. The use of English as the common language for computing-related disciplines 
A common language is very important in building an international community of scholars in a discipline. Greek, Latin, German, and French have provided such a common language for various communities at different times in history. The development of computers, although occurring in different countries, had major developments in the USA and the UK. This encouraged the use of English as the language for the computing field. As will be noted later, English was adopted as the language for the International Federation for Information Processing (IFIP). At the same time, there was a general recognition by scholars and business leaders of the value of an international language. English became the common language of international commerce and of research and education in many fields.

The common language of English has meant that international conferences on computing and information systems can be held at almost any location in the world, research is freely exchanged across boundaries, and textbooks and trade books are made available internationally.

3. The formation of the International Federation for Information Processing (IFIP) and its Technical Committee 8 (Information Systems)

In the early development of computing and its use in organizations, national organizations were forming, but there was no accepted international forum. The United Nations provided the impetus for the formation of an international information processing organization. UNESCO sponsored the first World Computer Conference in 1959 in Paris (eight years after the first commercial computer). This was followed by the organization in 1960 of the International Federation for Information Processing (IFIP) as a society of societies.

Technical work, which is the heart of IFIP's activity, is managed by a series of Technical Committees (TCs). Each member society (usually identified with a country) may appoint a representative to the governance committee for each technical committee. There are currently 12 technical committees. Each technical committee forms working groups. Individuals throughout the world may be members of a working group by demonstrating interest and continuing activity in the work of the group. In other words, the main scientific work of IFIP is accomplished by individuals without regard to country or other affiliation. The governance is organized to involve the societies that belong to IFIP (which for the most part are identified with countries).

The IFIP technical committee of interest in this view of the development of an international academic discipline is TC8 (Information Systems). It was established in 1976. Its aims are to promote and encourage the advancement of research and practice of concepts, methods, techniques, and issues related to information systems in organizations. Note that it was formed 25 years after the first use of computers in business. It currently has seven working groups.

- WG 8.1 Design and evaluation of information systems

- WG 8.2 Interaction of information systems and the organization

- WG 8.3 Decision support systems

- WG 8.4 E-business: multidisciplinary research and practice

- WG 8.5 Information systems in public administration 
- WG 8.6 Transfer and diffusion of information technology

- WG 8.8 Smart cards

The working groups of TC8 reflect some fundamental IS issues (WG8.1 on design and evaluation and WG8.6 on diffusion of IT innovation), the IS context (WG8.2 on interaction with organization and WG8.5 on public administration), and significant IS application areas (WG8.3 on decision systems, WG8.4 on e-business, and WG8.8 on smart cards).

TC8 was important in helping to build an international community. Its first chairman was Börje Langefors of Sweden. It started as somewhat Europe-centric but rapidly expanded to worldwide participation. I personally observed the building of that community. I was the second United States representative to TC8 and remained in that position for 20 years. I served as Chair of TC8 for two terms.

\section{International efforts by scholars in several countries}

It is difficult and somewhat dangerous to start mentioning specific names of important innovators and contributors. Even a casual reading of the history of inventions shows again and again that important innovations are "in the air." Several people are working on the same problem and coming to the same solutions, but one or only a few are recognized as the inventors. In the case of information systems as an academic discipline, there are a number of people who were critical in developing the field. These pioneers worked not only in their home countries but also in international organizations. They met at international conferences, took trips to become acquainted with what was happening in other places, and hosted visitors. They were founders and builders of the international societies that nourish the discipline today. The Association for Information Systems has recognized 13 of these by giving them the LEO award for lifetime exceptional achievement in information systems and 36 of them as AIS Fellows.

\section{Locating the IFIP TC8 working conferences internationally}

A strong comparative advantage of TC8 is its ability to draw together academics and other researchers in information systems from different countries and diverse cultural and academic backgrounds. The working group conferences became a vehicle for building an international network of scholars, both by the subjects of the conferences and the locations.

An example of how this has worked well is Working Group 8.2 on information systems and organizations. It is the group I worked with most, so my view is biased. This group now has an equal number of European and North American members plus members from other regions. The conference venues rotate in order to involve more researchers.

A very important conference in building the international community was the IFIP WG8.2 1984 Manchester Conference on information systems research methods (E. Mumford, R. Hirschheim, G. Fitzgerald, and T. Wood-Harper, 1985). 
The reason I count this conference as very important is its role in opening up the discussion of the different research paradigms. Most of the researchers in North America at that time tended to emphasize a positivist approach to research with experiments, surveys, hypothesis testing, and so forth. Many of the Europeans were doing post-positivist, interpretive research. The conference opened the minds of many of the conferees and helped open the field of information systems to a variety of research paradigms. Currently, there is reasonable, international acceptance of the following:

- Positivist, hypothesis testing, data-based research

- Interpretive research including research based on case studies

- Design science research

The IS research literature clearly defines the first two; the third is less well defined. Design science research (the term used by Smith and March) is based on the research paradigms of engineering and Computer Science. In design science, designing and building a new, novel artifact such as a computer application program, development methodology, or model is a contribution to knowledge. In general, information systems research publications have expected that an artifact will not only have been built but will also be tested to demonstrate proof of concept or value of the artifact. See $[5,6]$

\section{The founding of the International Conference on Information Systems (ICIS)}

As mentioned previously, early researchers in information systems had disciplines to which they belonged. Their conferences often provided opportunities to present information systems research. This was especially true of management science, operations research, and decision sciences. The IFIP working groups on information systems focused on information systems but tended to be around narrow topics. There was no general, well-accepted, high quality information systems conference.

The first Conference on Information Systems (later renamed as the International Conference on Information Systems or ICIS) was held in 1980. A major sponsor was the Society for Information Management, a society for CIOs. ICIS began as a North American conference but grew quickly to a high quality international conference. It was held in Copenhagen in 1990 and has been held outside the United States almost half of the time in the past 12 years. A major feature is a high quality, invitational doctoral consortium with a mix of doctoral students from different countries.

There has existed a very open attitude at ICIS to subgroups within the field. Several subgroups hold conferences immediately preceding or immediately following ICIS. Examples are the Workshop on Information System Economics (WISE), the Workshop on Information Technology Systems (WITS), IFIP WG8.2, and several others.

7. The founding in 1995 of the Association for Information Systems (AIS) with an international governance structure 
From the time of the first ICIS in 1980, there had been discussion of a new international organization devoted exclusively to the academic field of information systems. A poll of those attending ICIS in 1989 showed that academics were about evenly split on the issue. It became more and more evident that the lack of a single organization resulted in a lack of a strong voice in matters affecting the field.

The Association for Information Systems was formally established in 1995. The governance structure was designed to create a truly international organization. The position of president rotates among three regions: Americas, Europe-Africa, and Asia Pacific Area. AIS has grown to include close to 50 percent of faculty members worldwide.

AIS has allowed the field to concentrate and rationalize many of its resources. There has been an amalgamation of ICIS into AIS. It has taken over responsibility for preexisting assets of the field such as the Directories of IS Faculty, the past proceedings of ICIS, doctoral dissertation lists, survey of salaries for new hires, etc. It has created chapters and special interest groups. It maintains loose ties with many conferences and organizations that existed prior to its formation. AIS provides sponsorship support and doctoral consortia support for the three regional IS conferences.

AIS has two electronic journals: Communications of the AIS (CAIS) for communications about pedagogy, curriculum, and other issues in the field and Journal of the AIS (JAIS), a high quality academic journal. AIS entered into a partnership with The MIS Quarterly to provide this well established journal electronically to its members.

Information systems as an academic discipline clearly began in the developed countries. Many in the field have been concerned about reaching out to developing countries. IFIP has sponsored conferences in developing countries. AIS has initiated programs to make conferences available and less costly to faculty from developing countries. Since the cost of journals is a major impediment to developing countries, AIS has an outreach program that provides access to its e-journals, its proceedings, and the MIS Quarterly at a very nominal cost.

The Role of IFIP and TC8 in the Development and Nourishing of an Academic Discipline of Information Systems

By its very nature, IFIP did not contemplate the development of an academic discipline of computer science, computer engineering, information systems, etc. Rather, as a society of societies, it was to encourage international interaction and working conferences that would bring together participants from across the world. IFIP had a strong advantage in encouraging international cooperation and international workshops and conferences. This advantage stemmed from its role as a society of societies not identified with any one country.

IFIP had one very important weakness. It disseminated conference proceedings through high cost books marketed through a commercial publisher. Royalties provided significant revenues to IFIP, but it made the proceedings too costly for individual purchase. Sales were very low, primarily to libraries and to conference attendees. Recently, IFIP indicated proceedings are available online without cost through Springer.Com. On April 6, 2006, I examined the website and found 37 proceedings available online without cost. This may change the dynamics of distribution and improve use of IFIP proceedings 
The real work of IFIP is at the Working Group level. The Technical Committee coordinates the working groups and provides some oversight. It also sponsors some conferences. The question is the role of TC8 in encouraging the development of an academic discipline. I doubt than anyone in TC8 thought of its role in this way. They tended to think of encouraging international cooperation on important topics within the domain of information systems. They have done this very well but have tended to involve fairly small groups rather than large conferences.

Would TC8 have been a viable home for an international information systems academic society such as AIS? Probably not! IFIP was not designed to accomplish the task. The IFIP publications policy did not contemplate such an association. It would have embedded the IS group within a larger organization, and the community felt the need to be more visible and more independent.

Even though TC8 was not a suitable sponsor for an international academic society, the influence of TC8 working groups has been significant. This has been especially true of WG8.2. Its perspectives on important topics such as research methods, socio-technical systems, different views of systems, etc. have made an impact on the larger (perhaps more traditional) community.

\section{The Future of Information Systems as an Organization Function}

The future of information systems as an academic function is directly related to the future of the organization function. The reason for this strong connection is that a vital IS function provides employment for graduates of IS programs and provides interesting problems for research. An important organization function provides good evidence for the importance of the body of knowledge for IS academic activities. This section summarizes arguments in Davis et al., 2005. More detail can be found in that reference.

Information systems are an area of ongoing, major investment by organizations. The systems provide economic benefits and when combined with other organization systems may provide competitive advantage. Failure to employ information technology effectively may lead to significant organization risks and failures. Arguments that information systems can be outsourced may be applicable to a few activities but even if outsourced, they must be managed by an IS function. Arguments that information systems do not provide competitive advantage because technology can be easily acquired fail because the competitive advantage is not in the technology but in the technology-enabled systems as they are incorporated in the organization systems.

\section{Issues about the Future of Information Systems as an Academic Discipline}

Conditions for computer science and information systems education differ significantly by region and by country. In North America, there has been a dramatic 
drop in enrollments and faculty positions (although there are some signs that these are improving.) This downturn may be associated with unique conditions or it may signal an emerging enrollment problem everywhere.

One of the good effects of a downturn is that it causes an academic field to examine itself. The results are discussion about some critical issues that need to be resolved. Extreme pessimists may say that the outcome of the downturn will be the demise of the academic field. They make four arguments: recent drops in IS course enrollment, resistance to IS instruction for all students, resistance to IS as an academic field based on diversity or lack of coherence in research, and resistance in some universities to IS as a new academic discipline.

Drops in enrollment frequently reflect employment bubbles and changes in the employment market rather than fundamental changes in the nature of the organization function and the need for employment. The phenomenon of enrollment drops has happened in other fields, and they have stabilized after the market adjusts. The resistance to a first course for all students may reflect a need for a better course and also the ongoing pressure to reduce required courses. The remedy for a better course is in our hands; the pressure to reduce required courses can be negotiated if the course has high value. Diversity in research can be a weakness, but in the long run, it is probably a strength. It is not surprising that some established schools resist a new field, but it may not reflect on the value of the field. Innovation often comes from schools that are not comfortable and secure in their current position; schools with entrenched reputations often spurn innovation.

The future hinges externally on the vitality and importance of the information systems function. There is reason to view it optimistically. A vital, important function means employment and research opportunities for the IS academic discipline. There are opportunities to study and explain the organization, roles, duties, and operations of the IS function. All students in organization studies need to understand the IS function and its role in organization systems. This need provides a strong basis for the IS academic field. Most of the concerns about the academic field and its place in academia can be dealt with by the field itself. In the midst of concerns about the future, the IS academic faculty should keep in mind the comparative advantage of IS within the business and organization schools.

\section{Comparative Advantages of IS as an Academic Discipline}

In any discussion of the future and what is possible or likely, it is useful to understand not only weaknesses but also strengths and comparative advantages relative to competing fields. Within the broad academic area of organization studies, the IS academic discipline and IS faculty possesses several comparative academic advantages.

1 The IS academic field understands the IS organization function and what it does that is vital and important. Therefore, the IS field has a comparative advantage in teaching and researching the body of knowledge associated with the function. 
2 The IS academic field has a comparative advantage in its depth knowledge of technology-enabled organization systems. These systems are critical in modern organizations. The body of IS knowledge includes analysis of requirements, acquiring systems, operating the technology and support systems that provide services, and making sure the systems are available and secure. The trend toward integration internally and with suppliers and customers increases the importance of these system activities.

3 The IS academic field has a comparative advantage in its level of understanding of systems and systems thinking. Faculty members in other fields know something of systems but it is generally not central to their teaching or research. Students studying for work in organizations are trained in analysis, but they have virtually no training in systems concepts and systems thinking. This may be one of the most important deficiencies in their preparation. The IS function is prepared to correct this deficiency because systems thinking and systems concepts are central to the IS field and the design, implementation, and use of technology-enabled systems.

4 The IS field has a comparative advantage in modeling organizational behavior and data. The reason for this advantage is the centrality of this modeling to the design and implementation of systems and the use of databases by organization systems.

\section{Recommendations for Securing the Future}

Having described some issues and concerns and the comparative advantages of IS as an academic discipline, five recommendations are proposed for actions that will make a difference. These are explained in more detail in Davis et al., 2005.

a. Be proactive in defining our domain and articulating the importance of its parts.

b. Be aggressive in research and teaching at the fuzzy boundaries of applications with shared responsibilities. Every new IT-enabled organization work system is an opportunity for research.

c. Add real value to students in IS courses.

d. Be proactive as IS faculty members in keeping current on relevant technology and practice.

e. Be aggressive in adding value to IS practice and producing graduates prepared for a productive career.

A comment about recommendation 3 that we add real value to students in the IS courses. This appears to be difficult for non majors. In thinking about this issue, I think the answer is that these students should learn to do things that they can apply for years into the future. Examples are: defining requirements for an information system application; examining an existing system to evaluate its value and its deficiencies; evaluating quality, error-prone and error-prevention features of a system; and working with a system development project team. They need to be exposed to system concepts and socio-technical concepts. They need simple, useful 
frameworks for making sense of the systems they will encounter and the systems they will specify. They need to be able to understand how to think about new technologies and the affordances they offer and to envision new applications.

\section{Summary and Conclusions}

The purpose of this paper was to organize and present some of my thoughts, based on my experiences in developing the new IS academic discipline, with the objective of helping others to think about these issues. I often am asked why it happened the way it did. I provided the basis for my response. I am also asked what will happen in the future. I am an optimist, so my views are biased toward a favorable outcome. I explained the basis for my concerns and the basis for my optimism. I concluded with some prescriptions for things that need to be done to secure the future of the academic field.

\section{References}

1. G.B. Davis. Building an International Academic Discipline in Information Systems, in Bo Sundgren, Pär Mårtensson, Magnus Mähring and Kristina Nilsson, editors, Exploring Patterns in Information Management: Concepts and Perspectives for Understanding IT-Related Change, The Economic Research Institute (EFI), Stockholm School of Economics, Stockholm, Sweden, November 2003, pp. 273-290. Also available through the Electronic Bookstore of the Association for Information Systems.

2. G.B. Davis, A.P. Massey, and N. Bjørn-Andersen. Securing the Future of Information Systems as an Academic Discipline, in Proceedings of the International Conference on Information Systems, December 2005, pp. 979-990.

3. M. J. Culnan. The Intellectual Development of Management Information Systems, 1972-1982: A Co-Citation Analysis, Management Science 33:5, February 1986, pp. 156-172.

4. G.W. Dickson. Management Information Systems: Evolution and Status, in Advances in Computers, M. Yovits, editor, Academic Press, Vol 20, 1981, pp. 1-37.

5. A.J. Hevner, S.T. March, J. Park, and S. Ram, Design Science in Information Systems Research, MIS Quarterly, 28:1, 2004, pp. 75-105.

6. S.T. March and G.F. Smith. Design and Natural Science Research on Information Technology. Decision Support Systems, 15:4, 1995, pp. 251-266. 